\title{
TU/e EmonONEN

\section{Experimental study of oblique impact of particles on wet surfaces}

Citation for published version (APA):

Crüger, B., Heinrich, S., Antonyuk, S., Deen, N. G., \& Kuipers, J. A. M. (2016). Experimental study of oblique impact of particles on wet surfaces. Chemical Engineering Research and Design, 110, 209-219.

https://doi.org/10.1016/j.cherd.2016.01.024

\section{Document license:}

TAVERNE

DOI:

10.1016/j.cherd.2016.01.024

Document status and date:

Published: 01/06/2016

\section{Document Version:}

Publisher's PDF, also known as Version of Record (includes final page, issue and volume numbers)

\section{Please check the document version of this publication:}

-A submitted manuscript is the version of the article upon submission and before peer-review. There can be important differences between the submitted version and the official published version of record. People interested in the research are advised to contact the author for the final version of the publication, or visit the $\mathrm{DOI}$ to the publisher's website.

- The final author version and the galley proof are versions of the publication after peer review.

- The final published version features the final layout of the paper including the volume, issue and page numbers.

Link to publication

\section{General rights}

Copyright and moral rights for the publications made accessible in the public portal are retained by the authors and/or other copyright owners and it is a condition of accessing publications that users recognise and abide by the legal requirements associated with these rights.

- Users may download and print one copy of any publication from the public portal for the purpose of private study or research.

- You may not further distribute the material or use it for any profit-making activity or commercial gain

- You may freely distribute the URL identifying the publication in the public portal.

If the publication is distributed under the terms of Article 25fa of the Dutch Copyright Act, indicated by the "Taverne" license above, please follow below link for the End User Agreement:

www.tue.nl/taverne

Take down policy

If you believe that this document breaches copyright please contact us at:

openaccess@tue.nl

providing details and we will investigate your claim. 


\title{
Experimental study of oblique impact of particles on wet surfaces
}

\author{
Britta Crüger $^{a, *}$, Stefan Heinrich ${ }^{a}$, Sergiy Antonyuk ${ }^{b}$, Niels G. Deen ${ }^{c}$, \\ J.A.M. Kuipers ${ }^{d}$ \\ a Institute of Solids Process Engineering and Particle Technology, Hamburg University of Technology, \\ Denickestrasse 15, 21073 Hamburg, Germany \\ ${ }^{\mathrm{b}}$ Chair of Particle Process Engineering, Department of Mechanical and Process Engineering, \\ University of Kaiserslautern, Gottlieb-Daimler-Strasse, 67663 Kaiserslautern, Germany \\ c Multiphase \& Reactive Flows Group, Department of Mechanical Engineering, Eindhoven University of Technology, \\ P.O. Box 513, 5600 MB Eindhoven, The Netherlands \\ d Multiphase Reactors Group, Department of Chemical Engineering and Chemistry, \\ Eindhoven University of Technology, P.O. Box 513, 5600 MB Eindhoven, The Netherlands
}

\section{A R T I C L E I N F O}

\section{Article history:}

Received 31 August 2015

Received in revised form 5 January

2016

Accepted 19 January 2016

Available online 29 January 2016

Keywords:

Coefficient of restitution

Oblique collision

Impact

Liquid layer

Surface roughness

\begin{abstract}
A B S T R A C T
Granulation and agglomeration processes are characterized by intense particle-particle and particle-wall contacts. Furthermore, these collisions often happen in the presence of liquid layers due to liquid injection. Therefore the knowledge of micro-mechanics during wet collisions is fundamental for the exact description of such a process. In this work the collision behaviour of dry particles obliquely impacting a target plate covered by liquid layers is characterized by means of restitution coefficients. The coefficient of restitution describes the energy dissipation during an impact and is defined as the ratio of the velocities after and before impact. It is an important parameter for discrete element method (DEM) simulations and depends strongly on the collision parameters (such as collision velocity and angle), particle deformation behaviour (i.e. elastic or plastic) as well as on the properties of the injected liquid (viscosity, layer thickness). To investigate the influence of these parameters on the wet collision behaviour particle-wall impacts were recorded by two synchronized high-speed cameras allowing a three-dimensional analysis of the collision event. The focus of this work is to investigate the influence of liquid layer thickness, viscosity, surface tension and surface roughness on the normal and tangential coefficient of restitution.
\end{abstract}

(c) 2016 Institution of Chemical Engineers. Published by Elsevier B.V. All rights reserved.

\section{Introduction}

Dynamic processes involving solids are frequently used in various industries, such as chemical, food and pharmaceutical. Especially in granulation and agglomeration processes, for instance in fluidized beds (Salikov et al., 2015; Sutkar et al., 2015) and mixers (Neuwirth et al., 2013), the particles interact mutually or with the apparatus walls through a multitude of collisions. The energy dissipation during these collisions is fundamental for the characterisation and modelling of particle dynamics and is usually described by means of the coefficient of restitution $e$. The coefficient of restitution is defined as the ratio of the collision velocity after the collision $v_{R}$ and the velocity prior to the collision $v$. As such the coefficient of restitution characterizes the dissipation of kinetic energy $\left(E_{\text {diss }}\right)$ of the particles, with $E_{\text {kin }}$ and $E_{\text {kin,R }}$ before and after the impact.

$$
e=\left|\frac{v_{R}}{v}\right|=\sqrt{\frac{E_{\text {kin }, R}}{E_{\text {kin }}}}=\sqrt{1-\frac{E_{\text {diss }}}{E_{\text {kin }}}}
$$

\footnotetext{
* Corresponding author. Tel.: +49 40428783282.

E-mail address: britta.crueger@tuhh.de (B. Crüger). http://dx.doi.org/10.1016/j.cherd.2016.01.024

0263-8762/@ 2016 Institution of Chemical Engineers. Published by Elsevier B.V. All rights reserved.
} 
These collisions can happen in normal (perpendicular) direction or obliquely as well as between dry or (partially) wet particles, with the last drastically changing the collision behaviour. Wet particles may stick together after collision forming an agglomerate and leading to a coefficient of restitution of zero or they may rebound leading to distribution of the liquid between the particles. The coefficient of restitution under dry conditions was investigated extensively by different authors for the normal as well as the oblique case, e.g. Kantak et al., 2005; Antonyuk et al., 2010; Hastie, 2013; Kharaz et al., 2001; Dong and Moys, 2006; Jain et al., 2012, showing that energy dissipation depends mainly on the combination of the materials and the geometry of the colliding partners, the collision angle and in some respect also on the relative collision velocity. Kantak et al. (2005) observed that for normal impacts the dry coefficient of restitution of Teflon and steel spheres decreases with increasing collision velocity for normal impact velocities below $0.2 \mathrm{~m} / \mathrm{s}$, while Antonyuk et al. (2010) found the coefficient of restitution of four different materials to stay constant for velocities between 0.3 and $4.8 \mathrm{~m} / \mathrm{s}$. Jain et al. (2012) investigated normal collisions via simulations using a combined volume of fluid-immersed boundary method and were able to reproduce the phenomena experimentally observed by other authors. Wu et al. (2003) investigated normal rebound behaviour for dominantly plastic impacts using finite element methods and found the coefficient of restitution to decrease with increasing collision velocity and to depend on the ratio of Young's modulus to yield stress. For oblique impacts Kharaz et al. (2001) observed the normal coefficient of restitution of aluminium oxide particles to be approximately constant over a range of collision angles between $0^{\circ}$ and $85^{\circ}$. The tangential part of the coefficient of restitution however shows a strong dependence on the collision angle with a minimum in the range of $20^{\circ}$. These findings were supported by investigations of Antonyuk et al. (2010), who investigated oblique collisions of four different granules, and Dong and Moys (2006), who investigated oblique impacts of steel balls with and without initial spin. Furthermore, Dong and Moys' experiments indicated a strong dependence of the tangential coefficient of restitution on the initial spin of the particle before impact. The research group of Thornton (Wu et al., 2003, 2009; Thornton, 2009; Thornton et al., 2011, 2013) investigated dry oblique collisions using finite element methods and developed several models to describe normal and tangential coefficient of restitution as well as rotational behaviour for elastic and plastic materials.

If the particles are wetted by liquid layers or droplets on the surface, as happens in many solid processes for instance granulation and agglomeration, the coefficient of restitution depends on additional parameters, such as liquid viscosity, liquid layer thickness, particle size and strongly on the collision velocity. The wet restitution coefficient was investigated for normal collisions by several authors; see for instance (Kantak et al., 2005; Antonyuk et al., 2009; Fu et al., 2004; Dopfer et al., 2013; Gollwitzer et al., 2012). Kantak et al. (2005) showed for steel and Teflon balls impacting on a quartz plate covered by thin layers of silicone oil, that above a critical "sticking" velocity, below which no rebound occurs, the coefficient of restitution increases and ends in a plateau. These results were extended by Antonyuk et al. (2009), who additionally introduced a critical layer thickness and viscosity, which depend on the collision velocity. The coefficient of restitution decreases for increasing layer thickness or viscosity until critical values are reached. But still, the physics of wet collisions and especially the wet oblique collisions are not fully understood.

Several authors also started investigating the influence of surface roughness on dry and wet collisions. Barnocky and Davis (1988) showed for wet collisions that surface roughness has a considerably effect on rebound behaviour if roughness size exceeds a critical elasticity length scale of the solid material. Joseph et al. (2001) additionally demonstrated that surface roughness leads to an increase of scatter of experimental data regarding the coefficient of restitution. Ennis et al. (1991) developed a model based on viscous effects to describe granule consolidation and coalescence. This model predicts if colliding particles rebound or stick to each other after the impact using the dimensionless Stokes number and the surface roughness of the particles as parameters. Liu et al. (2000) extended the model of Ennis et al. including deformation of granules. However, these studies can not fully describe the influence of surface roughness on oblique collisions.

Therefore, this work focuses on the experimental investigation of particles obliquely colliding with a target plate covered by a liquid layer. Measurements were performed for glass spheres impacting a glass plate for different impact angles, liquid layer thicknesses, surface tension and liquid viscosities. Additionally, the influence of surface roughness of the particles and the target plate is analysed.

\section{Methodology}

\subsection{Experimental setup}

Fig. 1 illustrates the experimental setup used for this work, which is a further development of the setup by Crüger et al. (2015). Instead of the free-fall device the particle impact is initiated by an inhouse-designed particle accelerator that shoots the particle obliquely onto the plate. The impact angle can be adjusted freely and was varied between $0^{\circ}$ and $60^{\circ}$ by changing the orientation of the accelerator. To perform an impact a single particle is held on the tip of the particle accelerator with the aid of a vacuum pump. It is then accelerated without initial rotation in the direction of the target plate by a pressure surge of pressurised air via a magnetic valve. The collision of the particle and the target is recorded by two synchronized high-speed cameras (company Imaging Solutions models Y-4 and NX-4) with frame rates of 7000 fps. One camera captures the particle impact and rebound in the $x-y$-plane being positioned in front of the target, the second camera is positioned above the target recording the movement in $\mathrm{x}$ - and $z$-directions. Thereby, a three-dimensional analysis of the collision behaviour can be achieved. To get optimal illumination three LED lamps, two in front of the target and one behind, and a white background are used. The target is made of glass with a size of $\mathrm{W} \times \mathrm{L} \times \mathrm{H}=80 \times 80 \times 10 \mathrm{~mm}^{3}$. It is bordered by a $1 \mathrm{~cm}$ wide and approximately $200 \mu \mathrm{m}$ thick polymer ring on the impact side to keep the liquid layer from running off. Furthermore, the target can be rotated by a positioning table to guarantee a perfectly horizontal position and thus a uniform liquid layer. The thickness of the liquid layer is controlled before each impact test by means of an optical confocal sensor (Micro Epsilon confocalDT IFS2405-1) with a measuring error of less than $1 \mu \mathrm{m}$.

The normal and tangential components of the coefficient of restitution $e_{n}$ and $e_{t}$ are calculated from image series by a Matlab script (company Mathworks) analogous to Eq. (1). Rebound velocities are measured directly after rupture of the 
(b)

(a)

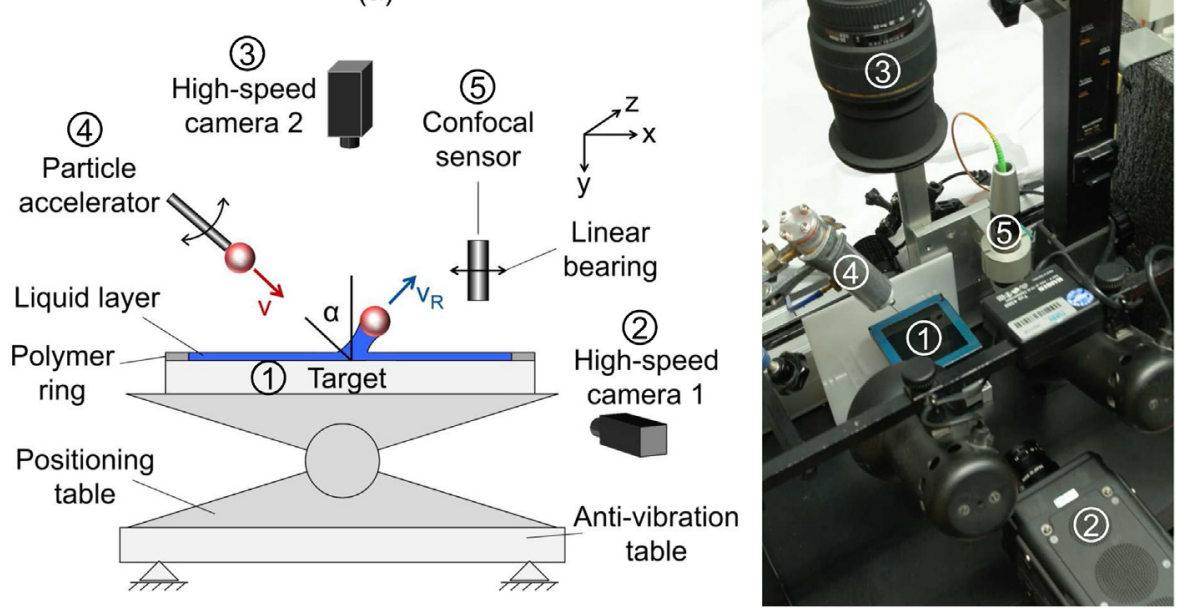

Fig. 1 - The experimental setup for measuring the coefficient of restitution of a particle impacting on a target plate covered with a liquid layer: (a) schematic representation of the total set-up, (b) snapshot of actual set-up.

liquid bridge, which time of occurrence is characteristic for each configuration of collision parameters.

$e_{n}=\left|\frac{v_{n, R}}{v_{n}}\right|$

$e_{t}=\left|\frac{v_{t, R}}{v_{t}}\right|$

For each configuration of collision parameters at least 30 experiments were conducted to get reliable results. Standard deviations are shown for each mean value.

During all experiments the normal impact velocity was set constant at approximately $1.05 \mathrm{~ms}^{-1}$. Thus, with increasing collision angle from the vertical the tangential impact velocity and accordingly the total impact velocity increase as well.

The total velocity $v_{\text {tot }}$ can be calculated by $v_{\text {tot }}=\sqrt{v_{n}^{2}+v_{t}^{2}}$.

\subsection{Materials}

Glass beads (Swarco Type S) with a mean diameter of $1.74 \mathrm{~mm}$ were used as particles. The particles are closely sized, have a high sphericity, measured with the Camsizer XT (Retsch Technology), and no porosity, as can be seen in Fig. 2. The used glass particles behave dominantly elastic at impacts in the investigated range of collision velocities and show only little dissipation of collisional energy for dry collisions $\left(e_{d r y} \approx 0.96\right)$. Therefore, they are a nearly ideal model material to investigate the influence of liquid on the collision behaviour. To investigate the influence of surface roughness the glass particles' surface was roughened by sand in a roller drum and the target plate by sand blasting. Table 1 summarises the obtained surface roughness measured 25 times with a Alicona Infinite Focus (Alicona Imaging $\mathrm{GmbH}$ ) with a $20 \times$ objective at a vertical resolution of $50 \mathrm{~nm}$ and a lateral resolution of $2 \mu \mathrm{m}$. As threshold wavelength $\lambda_{c}=40 \mu \mathrm{m}$ was chosen. The original target plate's surface was too smooth and reflective to be analysed by Alicona Infinite Focus, therefore, it is assumed to be equal or even less rough than the original smooth particles and therefore, surface roughness can be neglected.
Table 1 - Surface roughness of the used materials.

\begin{tabular}{lcc} 
Material & $\begin{array}{c}\text { Mean surface } \\
\text { roughness } \mathrm{S}_{a} / \mu \mathrm{m}\end{array}$ & $\begin{array}{c}\text { Standard } \\
\text { deviation } / \mu \mathrm{m}\end{array}$ \\
\hline original smooth particles & 0.32 & 0.07 \\
Rough particles & 0.67 & 0.05 \\
Rough target plate & 1.31 & 0.03 \\
\hline
\end{tabular}

Table 2 - Viscosity and surface tension of aqueous glycerol solutions at $20^{\circ} \mathrm{C}$ (Glycerine Producers Association, 1963).

\begin{tabular}{ccc}
$\begin{array}{l}\text { Glycerol } \\
\text { concentration/wt\% }\end{array}$ & Viscosity/mPa s & $\begin{array}{c}\text { Surface ten- } \\
\text { sion } / \mathrm{mN} \mathrm{m}^{-1}\end{array}$ \\
\hline 0 & 1 & 72.8 \\
50 & 6 & 68.2 \\
75 & 35.5 & 65.9 \\
100 & 1410 & 63.4 \\
\hline
\end{tabular}

As liquid layer distilled water and aqueous glycerol solutions with a layer thickness between 200 and $600 \mu \mathrm{m}$ as well as an aqueous solution of Tween 20 (Polyethylene glycol sorbitan monolaurate, company Sigma-Aldrich Co. LLC.) were used. The viscosity of aqueous glycerol is in the range between $1 \mathrm{mPas}$ for pure water and $1410 \mathrm{mPa}$ for pure glycerol at $20^{\circ} \mathrm{C}$ and is given in Table 2 for different concentrations (Glycerine Producers' Association, 1963). The surface tension of these solutions is $72.8 \mathrm{mN} \mathrm{m}^{-1}$ for water, $63.4 \mathrm{mN} \mathrm{m}^{-1}$ for glycerol and nearly linear in between (Glycerine Producers' Association, 1963). The concentration of Tween 20 solution was chosen at $60 \mathrm{mgl}^{-1}$, which Helenius et al. (1979) indicate as the critical micelle concentration (CMC). Surface tension of this solution is $37.3 \mathrm{mN} \mathrm{m}^{-1}$, measured by Du-Noüy-method in a K100 Force Tensiometer (company Krüss $\mathrm{GmbH}$ ), the viscosity is in the range of water, measured in the RHEOTEST RN 4.1 (company RHEOTEST Medingen $\mathrm{GmbH}$ ). The quasi-static wetting angle of water, glycerol and the Tween 20 solution were determined by sessile drop method as $29 \pm 3^{\circ}$ for water, $37 \pm 3^{\circ}$ for glycerol and $20 \pm 2^{\circ}$ for the Tween 20 solution. The temperature was controlled at $21^{\circ} \mathrm{C}$ during the measurements. 
(a)

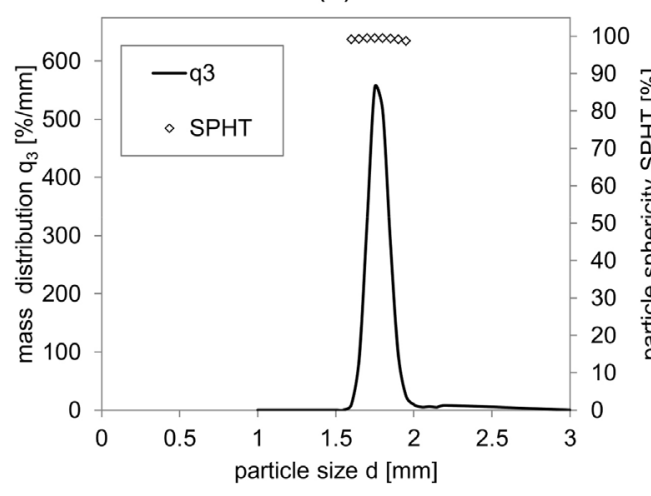

(b)

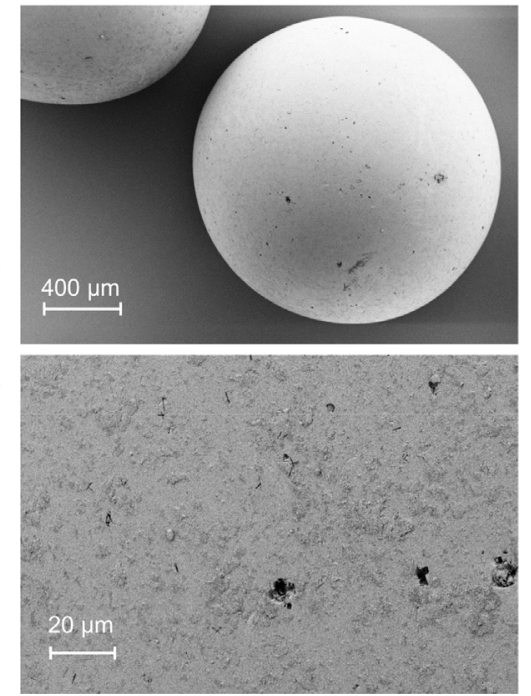

Fig. 2 - Characteristics of the used glass particles: (a) particle size distribution and sphericity measured by a Camsizer XT (Retsch Technology); (b) SEM images with 100x and 2000x magnification.

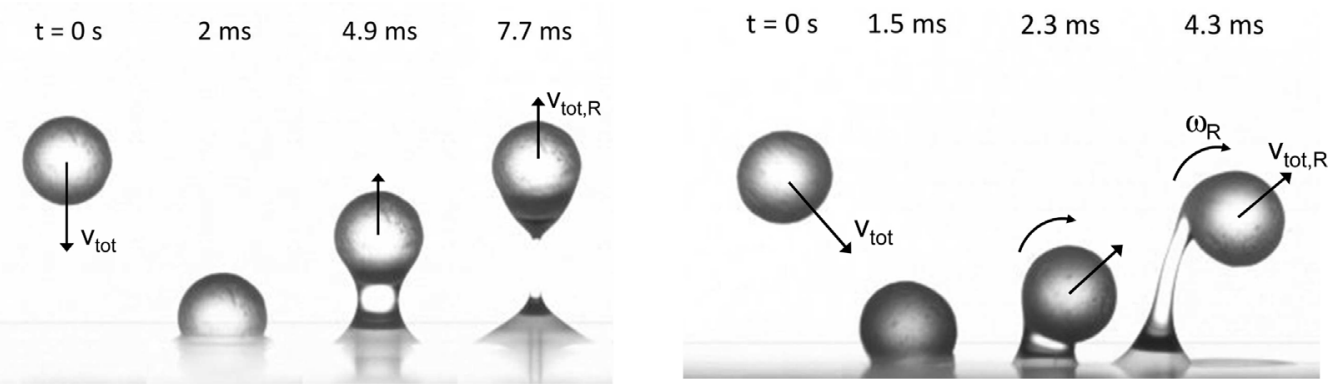

Fig. 3 - Image series of normal (left) and oblique (right) collisions visually comparing the difference in formation and shape of the liquid bridge between particle $\left(d_{P}=1.74 \mathrm{~mm}\right)$ and wall.

\section{Results and discussion}

The differences between normal and oblique collisions of particles and walls in the presence of liquid layers can already be observed visually, for example in Fig. 3. The shape of the liquid bridge that forms during rebound after normal collisions is rotationally symmetric and concave, while it gets deformed during oblique collisions due to the tangential movement and rotation of the particles after the impact. Accordingly dissipative forces, such as capillary and viscous forces, should differ between normal and oblique collisions resulting in a dependence of the energy dissipation on the collision angle.

\subsection{Oblique collision and influence of layer thickness}

Figs. 4 and 5 demonstrate the dependence of the normal and tangential coefficient of restitution on the collision angle for a changing thickness of water layers on the target at a constant normal collision velocity of $1.10 \pm 0.13 \mathrm{~ms}^{-1}$. However, as Fig. 4(a) shows, the normal coefficient of restitution is independent of the collision angle in the dry case without a water layer on the target as well as during collisions with a liquid layer. The application of a $200 \mu \mathrm{m}$ thick liquid layer on the target leads to a decrease of the coefficient of restitution from a mean value of 0.96 for the dry case to approximately 0.74 with water. An increase of the layer thickness to $400 \mu \mathrm{m}$ causes a further decrease of the normal coefficient of restitution to approximately 0.61 , while the overall dependence on the collision angle remains nearly constant. This decrease results from the particles staying longer time partially submerged in liquid. Therefore, dissipative forces can act on the particle during a longer period of time. The independence from the collision angle can be explained by the constant normal impact velocity. Although penetration distance increases with increasing collisions angle, the tangential velocity proportionally increases. Thus the particles are submerged in the liquid approximately the same period of time for all impact angles leading to the shown independence of the collision angle. As can be seen in Fig. 4(b) the decrease of the normal coefficient of restitution due to increasing layer thickness has a linear trend and is independent of the collision angle as was mentioned before. These results lead to the conclusion that the normal coefficient of restitution is only dependent on the normal collision velocity, as was shown in our previous work (Crüger et al., 2015), but independent of the tangential velocity. This has already been reported by $\mathrm{Ma}$ et al. (2015) for different collision angles between $10^{\circ}$ and $20^{\circ}$, which can be confirmed for a larger range of collision angles up to $60^{\circ}$ in this work. Wu et al. (2003) however, found the normal coefficient of restitution of dominantly plastic materials to increase with increasing collision angle in a study using finite element models. Since the particles investigated in this work are nearly ideal elastic the findings of $\mathrm{Wu}$ et al. cannot be validated. The linear dependence of the normal coefficient of restitution on the layer thickness has already been reported by several authors, e.g. (Antonyuk et al., 2009; 


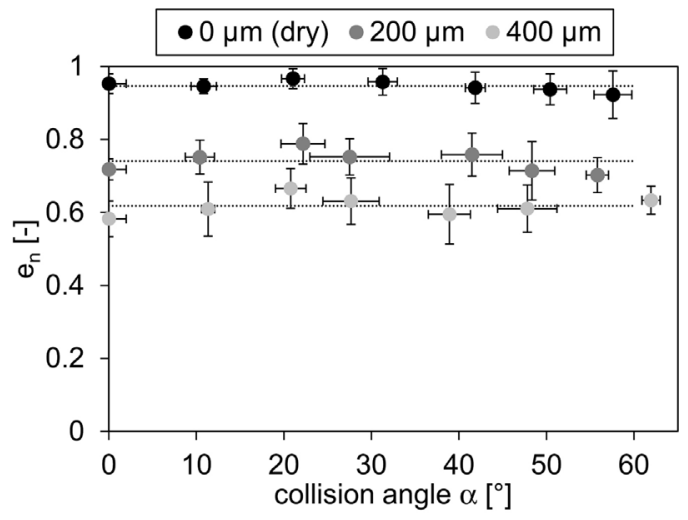

(a)

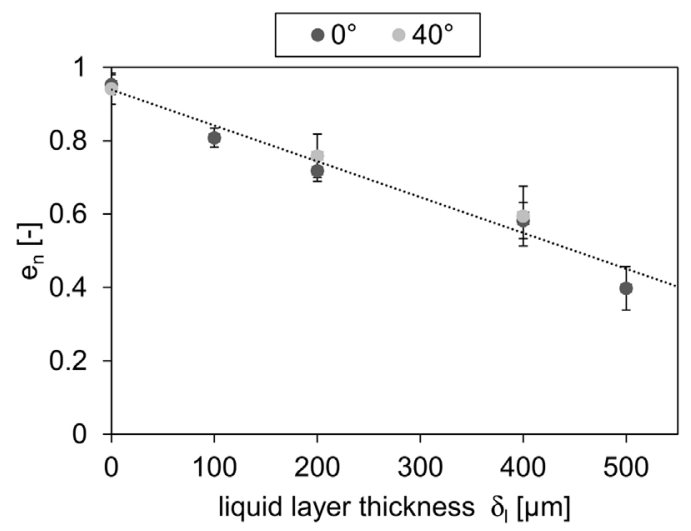

(b)

Fig. 4 - Normal coefficient of restitution as function (a) of the collision angle for different thicknesses of water layers on the target and (b) of the thickness of water layers for two different collision angles at a constant normal collision velocity of $1.10 \pm 0.13 \mathrm{~ms}^{-1}$.

Kharaz et al., 2001; Crüger et al., 2015), for normal collisions but applies to oblique collisions as well.

The tangential coefficient of restitution on the contrary shows a dependence on the collision angle. For dry collisions it features a minimum at about $30^{\circ}$ and ranges between 0.67 and 0.8 and is thus always lower than the normal coefficient of restitution in the dry state. Antonyuk et al. (2010) described a similar behaviour for the oblique impact of three different types of granules. For all granules a minimum in the

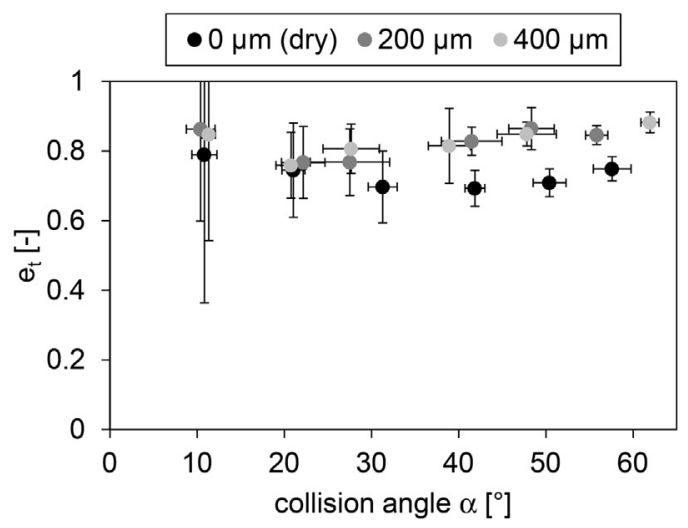

Fig. 5 - Tangential coefficient of restitution as function of the collision angle for different thicknesses of water layers on the target at a constant normal collision velocity of $1.10 \pm 0.13 \mathrm{~ms}^{-1}$. tangential coefficient of restitution exists and varies only slightly in the collision angle, where the minimum is located. Antonyuk et al. (2010), Kharaz et al. (2001) as well as Dong and Moys (2006) stated that this minimum can be explained by a transition from rolling to sliding friction between particle and target. Therefore, translational kinetic energy in the tangential direction is converted to rotational energy leading to a decrease in the tangential coefficient of restitution.

If a liquid layer, in this case water, is added to the surface of the target the tangential coefficient of restitution is higher than for dry conditions and seems to shift the minimum to approximately $20^{\circ}$. This shift of the minimum however cannot be solidly ascertained, because the standard deviation of the tangential coefficient of restitution at collisions angles of $10^{\circ}$ is especially large with a standard deviation of up to $50 \%$ of the mean value.

A closer look at the standard deviations of the tangential coefficient of restitution shows increasing scatter of the experimental data with decreasing collision angle. At small collision angles the tangential impact as well as rebound velocities are rather small (below $0.25 \mathrm{~ms}^{-1}$ ). Therefore, a small deviation of the rebound velocity or angle posses a considerable effect on the coefficient of restitution leading to such high scatter. Such deviations can occur due to imperfection of a nearly spherical form of the particles or because of different surface roughness on each particle's surface. Also micro-cracks forming inside or on the surface of the particle during the impact can change the friction and deformation behaviour at the contact and therefore lead to scatter in the rebound behaviour. Accordingly, the increasing scatter with decreasing collision angle is normal and should also occur in actual granulation processes. Especially for irregularly shaped particles the scatter in rebound behaviour will increase exceedingly.

An increase of the layer thickness seems to have neither an effect on the value of tangential restitution nor on the overall dependence on the collision angle in the investigated range. From these results it can be assumed that a liquid layer reduces energy dissipation during impact. This can be explained by a lubrication effect of the liquid. This lubrication would also explain the shift of the minimum to smaller angles since the liquid enhances sliding of the particle on the target. However, a change of layer thickness seems to have no further influence on the friction between particle and plate and therefore no influence on the tangential coefficient of restitution. In accordance to the findings of Antonyuk et al. (2010), Kharaz et al. (2001) and Dong and Moys (2006) mentioned above sliding leads to less rotation than rolling. Therefore, it can be assumed that the application of a liquid layer and the thus resulting lubrication effect reduces particle rotation. The findings of $\mathrm{Ma}$ et al. (2015) support this statement, showing a decrease of the angular velocity of $\mathrm{Al}_{2} \mathrm{O}_{3}$ particles impacting on a stainless steel plate after addition of liquid layers.

\subsection{Viscosity}

An increasing viscosity of glycerol solutions leads to a strong decrease of the normal coefficient of restitution but no change of the dependence on the collision angle (constant in the investigated range), as can be seen in Fig. 6 . The decrease of the mean value continues with increasing viscosity until the normal coefficient of restitution reaches zero and the particle sticks to the liquid on the target wall. This result supports the findings of for example Antonyuk et al. (2009), Gollwitzer et al. 


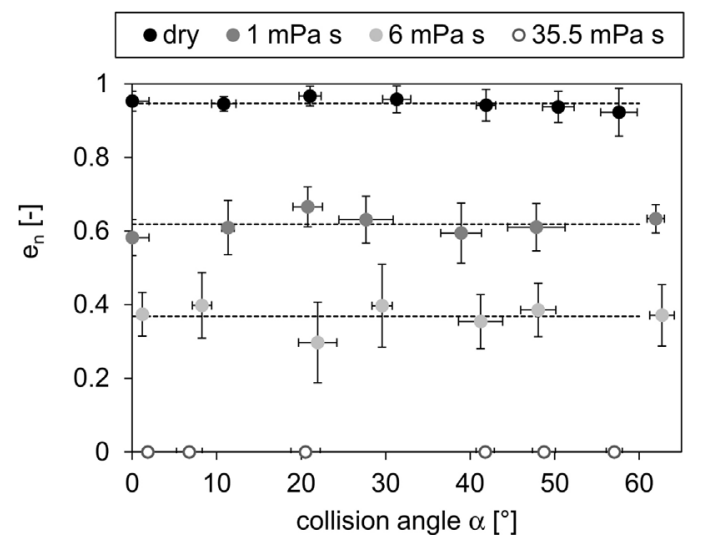

Fig. 6 - Normal coefficient of restitution as function of the collision angle for different viscosities of a liquid layer of $400 \mu \mathrm{m}$ thickness at a constant normal collision velocity of $1.07 \pm 0.16 \mathrm{~ms}^{-1}$.

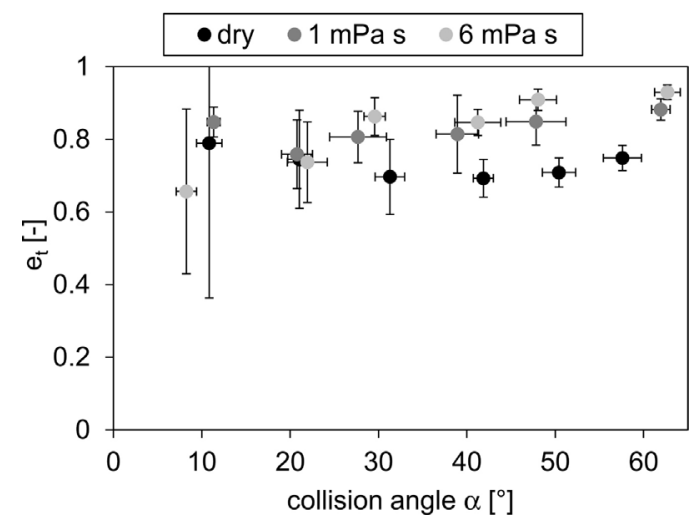

Fig. 7 - Tangential coefficient of restitution as function of the collision angle for different viscosities of a liquid layer of $400 \mu \mathrm{m}$ thickness at a constant normal collision velocity of $1.07 \pm 0.16 \mathrm{~ms}^{-1}$.

(2012), who investigated the influence of viscosity on normal collisions, and of Ma et al. (2013), who performed first studies on the influence of viscosity during oblique collisions. One explanation is an increase of the viscous force with increasing viscosity of the liquid and therefore an increasing energy dissipation.

The tangential coefficient of restitution also shows a dependence on the viscosity as displayed in Fig. 7. As mentioned above, when a liquid layer is applied to the target the tangential coefficient of restitution increases and the minimum seems to shift to smaller angles compared to dry collisions. With increasing viscosity the tangential coefficient of restitution slightly increases further, while the minimum seems to disappear. However, as was mentioned before the data at collision angles of less than $20^{\circ}$ are featured by extremely high standard deviations making conclusions in this range impossible. The assumption of a shifting minimum would lead to the guess, that an increasing viscosity enhances sliding of the particle on the target causing a transition from rolling to sliding at smaller collision angles than for lower viscosities. Ma et al. (2015) also found the rotational velocity of particles colliding with a wet plate to decrease with increasing viscosity, supporting the assumption of a change in the transition regime between rolling and sliding.

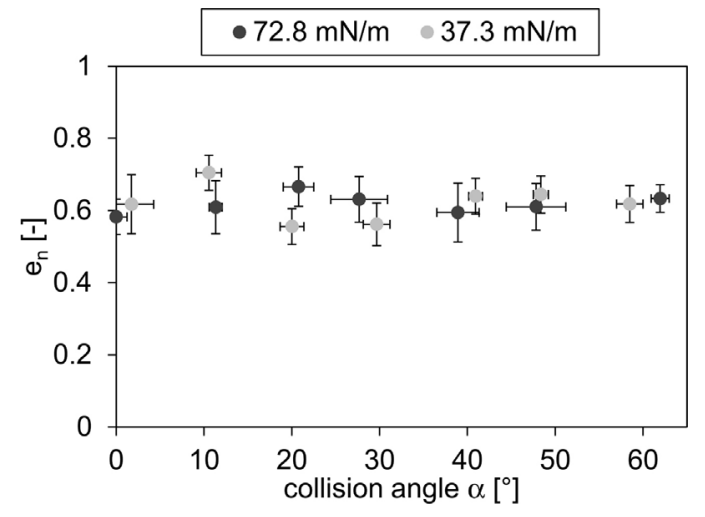

Fig. 8 - Normal coefficient of restitution as function of the collision angle for different surface tensions of a liquid layer of $400 \mu \mathrm{m}$ thickness at a constant normal collision velocity of $1.06 \pm 0.11 \mathrm{~ms}^{-1}$.

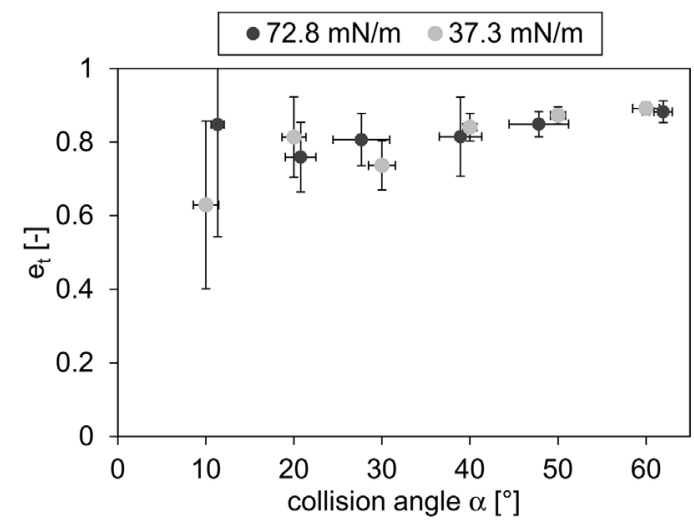

Fig. 9 - Tangential coefficient of restitution as function of the collision angle for different surface tensions of a liquid layer of $400 \mu \mathrm{m}$ thickness at a constant normal collision velocity of $1.06 \pm 0.11 \mathrm{~ms}^{-1}$.

\subsection{Surface tension}

Figs. 8 and 9 show the normal and tangential coefficients of restitution over the collision angle for two liquids with different surface tensions, first water and second the aqueous Tween 20 solution. For both liquids the normal coefficient of restitution is still independent of the collision angle. Although there seem to be some small deviation between the two liquids, the mean values for both solutions are approximately the same, with 0.618 for water and 0.620 for Tween 20 solution. Therefore, the normal coefficient of restitution can be considered to be independent of the surface tension in the investigated range of surface tension and particle properties.

Also the tangential coefficient of restitution shows no considerable dependence on surface tension for collision angles above $20^{\circ}$. Only the values at $10^{\circ}$ differ with a smaller tangential coefficient of restitution for lower surface tension, but both values still keep in each others standard deviations, again showing strong scatter of the experimental data.

Accordingly both the normal and the tangential coefficients of restitution can be regarded as independent of the surface tension for the investigated range of properties. For smaller particles and layer thickness however, it can be assumed, that surface tension may have some influence on the coefficients of restitution since e.g. viscous forces are less pregnant in that case, as was also determined by Antonyuk et al. (2009). They calculated the energy dissipation during 

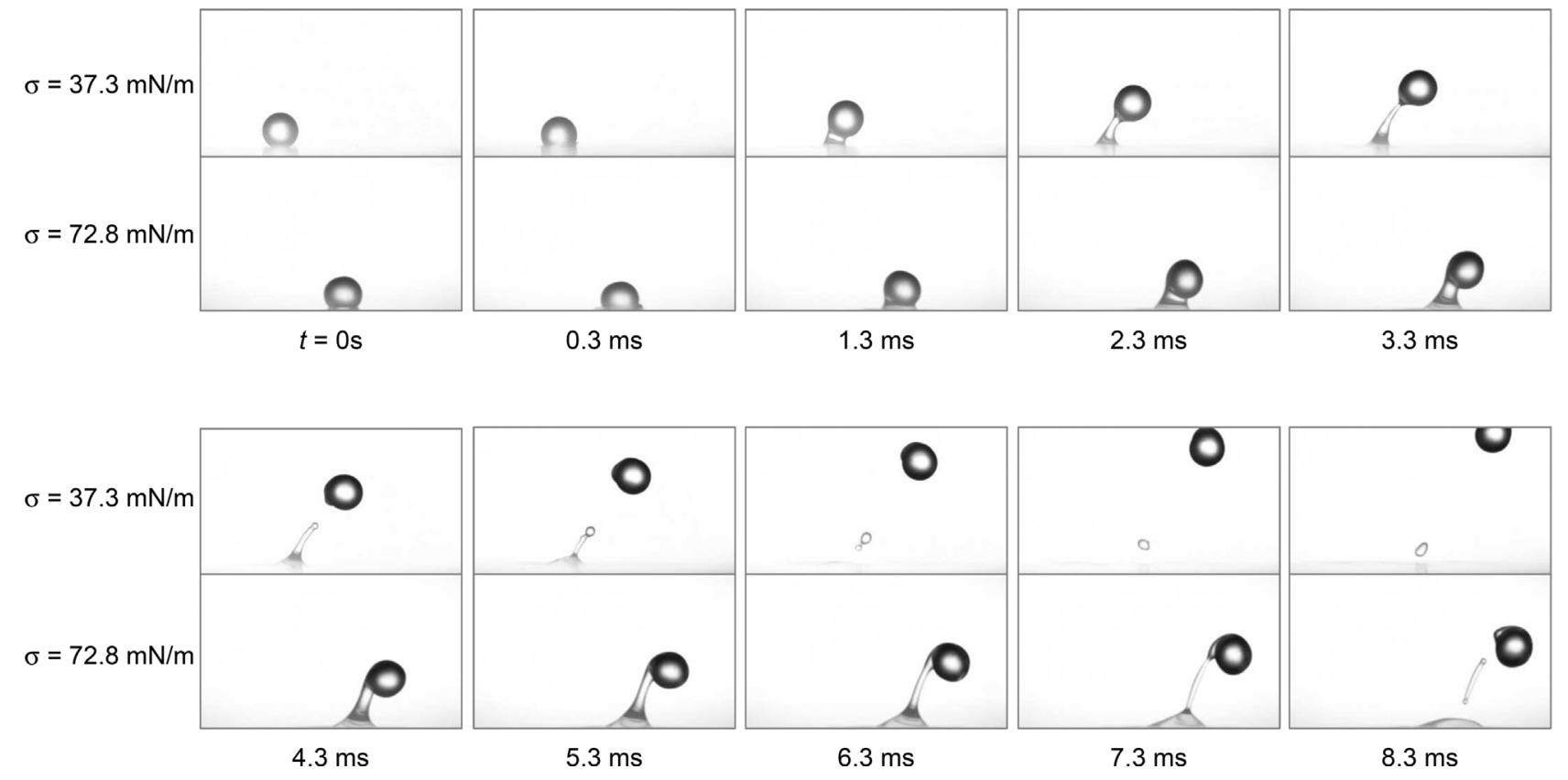

Fig. 10 - Comparison of the rebound behaviour of a glass particle impacting on a $400 \mu \mathrm{m}$ layer of liquids with two different surface tensions.
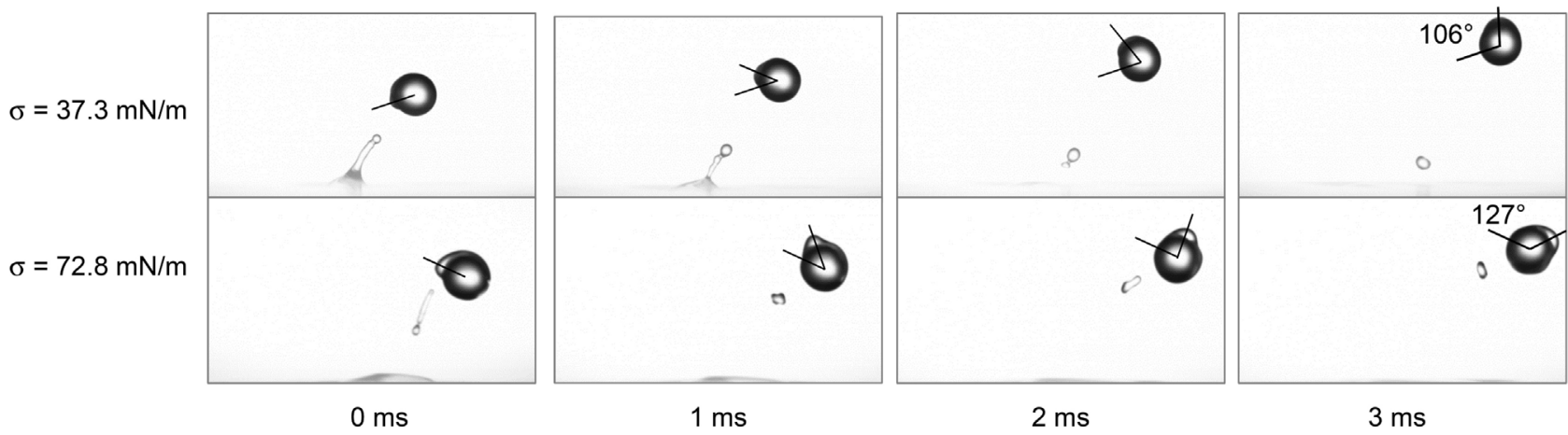

Fig. 11 - Comparison of the rotation of a glass particle after impacting on a $400 \mu \mathrm{m}$ layer of liquids with two different surface tensions.

a normal collision of a particle with a wet wall via force balance models and found that capillary and surface tension forces can be neglected for higher layer thickness as have been investigated in this work. But for thin liquid layers and small velocities, which were not investigated in this study, the surface tension might still have some influence on the coefficients of restitution.

However, with a closer look at the rebound behaviour and formation and rupture of the liquid bridge for both surface tensions in Fig. 10, it can be seen that there seem to be some differences in rebound behaviour. These differences result from the change of surface tension and also from a change of wetting behaviour due to the varying surface tension. One change in rebound behaviour is, that the time after rebound, when the liquid bridge ruptures, is much shorter for a smaller surface tension ( $3.3 \mathrm{~ms}$ for Tween 20 to $7.3 \mathrm{~ms}$ for water). Also the form of the liquid bridges changes with varying surface tension. It is thinner for lower surface tension and the contact point between liquid bridge and particle is positioned more or less on the lower left side of the particle for a small surface tension while it is located on the left side for the higher surface tension of water. Fig. 11 shows a sequence of images for both surface tension directly after rupture of the liquid bridge. The particle, which impacted on the liquid with higher surface tension, seems to rotate slightly faster than the one, that collided
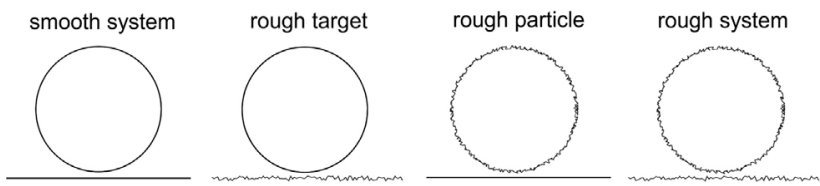

Fig. 12 - Different roughness combinations of the collision partners.

with the liquid of lower surface tension. Therefore, it would be interesting to quantify, if with increasing surface tension the post-rotation of the particle might increase, because the liquid bridge might cause a torque on the particle leading to more rotation.

\subsection{Surface roughness}

The influence of surface roughness on the normal and tangential coefficients of restitution were analysed by four different roughness combinations, shown in Fig. 12. Therefore, the particles and target plates described in Section 2 are combined in different compositions: The first system will be indicated as "smooth" system, which is the standard system consisting of the smooth particles impacting on the smooth target. In the second system smooth particles collide with the roughened target plate. It is thus regarded as system with "rough 


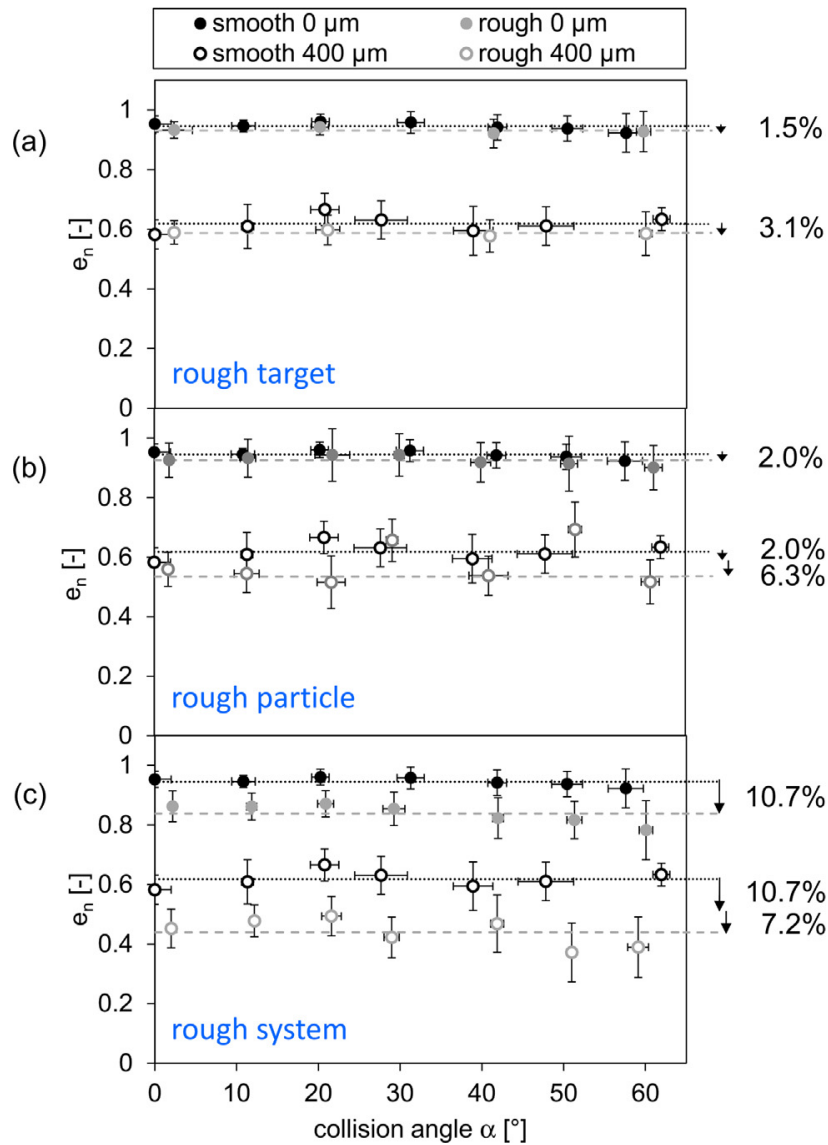

Fig. 13 - Normal coefficient of restitution as function of the collision angle comparing the smooth system to (a) the system with rough target, (b) the system with rough particles and (c) the completely rough system at a constant normal collision velocity of $1.04 \pm 0.07 \mathrm{~ms}^{-1}$. Solid symbols represent dry collisions and open symbols show collisions on a $400 \mu \mathrm{m}$ water layer.

target plate". Accordingly the third combination is called system with "rough particle", where rough particles impact on the smooth target. The pairing of rough plate and rough particles gives the "rough system".

Fig. 13 shows the normal coefficient of restitution over the collision angle for the different roughness combinations. The upper graph (a) compares the smooth system with the system where only the target plate was roughened (measurements for the rough plate only at collision angles of $0^{\circ}, 20^{\circ}, 40^{\circ}$ and $60^{\circ}$ ). Only minor influence of the surface roughness both in the dry case and the wet case with a $400 \mu \mathrm{m}$ thick water layer can be found. The normal coefficient of restitution only decreases by approximately $1.5 \%$ and $3.1 \%$, respectively, while the standard deviation of the measurements is about $1-1.5 \%$ of the mean value. The $99 \%$ confidence interval for the mean values averaged over collision angle are below $\pm 1.1 \%$. Therefore, the small differences of $3.1 \%$ in the most are neglectable regarding statistical confidence.

The middle graph (b) gives the influence of the system, where only the particles are rough. In the dry case again only minor dependence of the normal coefficient of restitution is detected. However, for rough particles impacting on a smooth target covered with a water layer of $400 \mu \mathrm{m}$ thickness a stronger decrease of the normal coefficient of restitution of $8.3 \%$ in total is detected (values at $30^{\circ}$ and $50^{\circ}$ taken as outlier, otherwise $4.3 \%$ ). If the influence during dry collisions of $2 \%$ is subtracted from this, it can be concluded that some additional part of the kinetic energy of approximately $6.3 \%$ is dissipated by surface roughness inside the liquid layer. Although the standard deviation of each measurement is approximately $10 \%$ of each mean value, the standard deviation of the normal coefficient of restitution averaged over the collision angles amount to less than $4 \%$ and a $99 \%$ confidence interval below $\pm 1.25 \%$. Therefore, some influence of the particles surface roughness can be concluded for wet collisions.

If the completely rough system is compared to the smooth system in the lower diagram (c) the surface roughness leads to a decrease of already about $10.7 \%$ in the dry case, which might arise from plastic deformation or fracture of the roughness peaks or from linkings forming between both rough surfaces, which have to be overcome. This strong difference in the influence of roughness during dry collisions between the case if only one collision partner is rough and the case with both rough surfaces, leads to the assumption that a critical value of the total surface roughness exists, which has to be overcome to have an influence of the surface roughness. A look at the wet impact shows that the rough system has a normal coefficient of restitution that is even $17.9 \%$ lower compared to the smooth system. Although the standard deviation for this wet collision in the completely rough system is about $10 \%$ of the averaged coefficient of restitution, nevertheless the $99 \%$ confidence interval is $\pm 1.25 \%$ and thus a clear decrease can be seen. If again the change in the dry case is subtracted from that in the wet collision, a decrease due to the liquid layer of $7.2 \%$ can be found. This value is in the same order of magnitude as the influence of the liquid layer for rough particles impacting on the smooth target (6.3\%). This leads to the assumption, that the surface roughness of the particle causes a characteristic decrease of the normal coefficient of restitution by approximately $6-7 \%$ for a particle surface roughness as used in this work. This decrease due to the movement of the rough particle in the liquid layer can be explained by an increasing drag force due to increasing surface roughness.

The decrease of normal coefficient of restitution with increasing surface roughness shown for the rough system contradicts the model of Ennis et al. (1991). They proposed a model that predicts if two wet particles rebound or stick together after a normal collision, taking into account only viscous forces neglecting all other dissipative forces. A critical Stokes number $\mathrm{St}^{*}$ was introduced, below which no rebound occurs. St includes the particles surface roughness $\varepsilon$, layer thickness $\delta_{l}$ and dry coefficient of restitution and is defined as

$\mathrm{St}^{*}=\left(1+\frac{1}{e_{\mathrm{dry}}}\right) \cdot \ln \left(\frac{\delta_{l}}{\varepsilon}\right)$

This model predicts for increasing surface roughness a decrease of critical Stokes number and therefore an increase of the critical layer thickness leading to less sticking. Less sticking moreover implies a larger coefficient of restitution. This disagrees with the findings of this work, where a decrease of normal coefficient of restitution was found with increasing surface roughness.

In Fig. 14 the influence of surface roughness on the tangential coefficient of restitution is displayed. Again the upper diagram (a) compares the results for the smooth system and the system with rough target plate for dry collisions and with a water layer of $400 \mu \mathrm{m}$ thickness. There seems to be no difference between the tangential coefficient of restitution for dry collisions. For the wet case the smooth system shows 
(a)

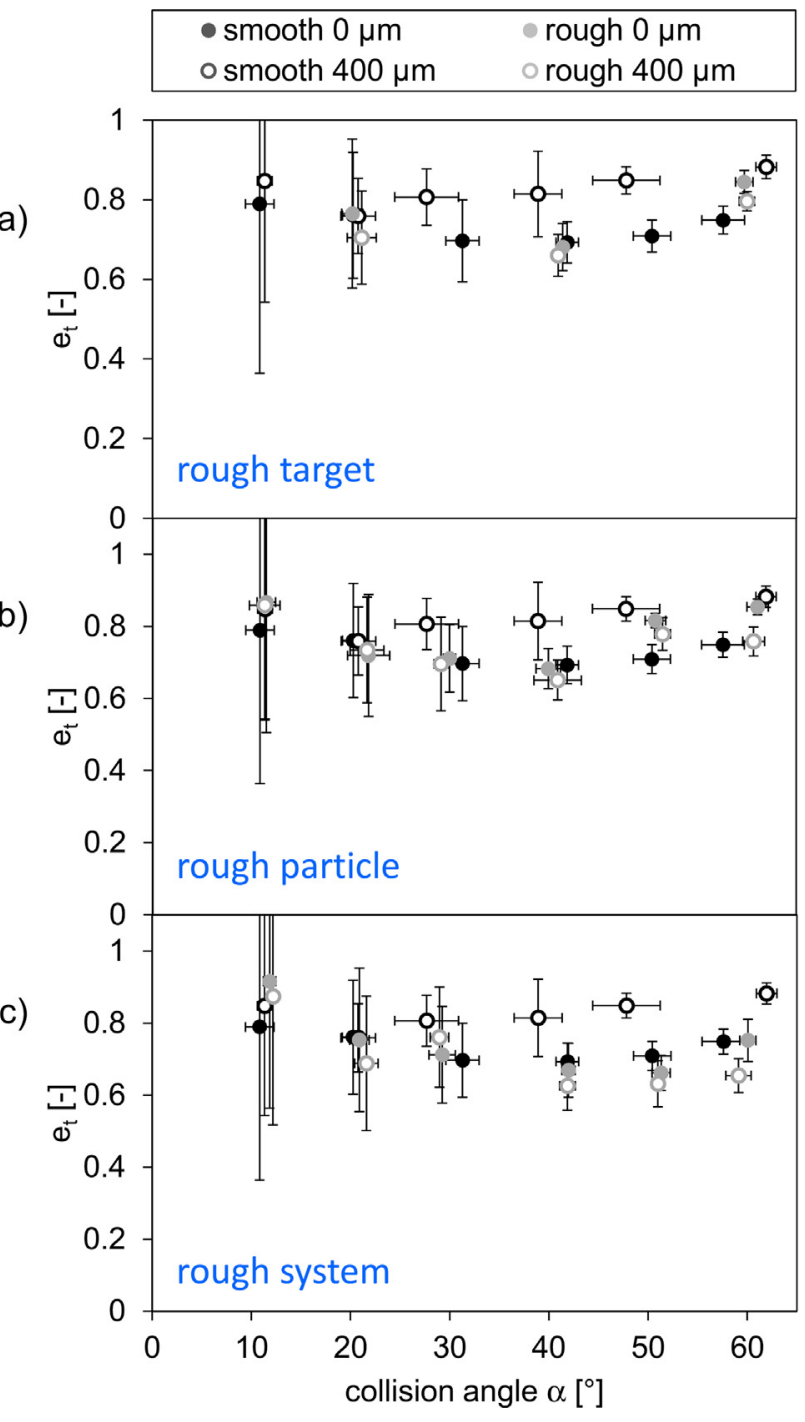

Fig. 14 - Tangential coefficient of restitution as function of the collision angle comparing the smooth system to (a) the system with rough target, (b) the system with rough particles and (c) the completely rough system at a constant normal collision velocity of $1.04 \pm 0.07 \mathrm{~ms}^{-1}$. Solid symbols represent dry collisions and open symbols show collisions on a $400 \mu \mathrm{m}$ water layer.

an increase of the tangential coefficient of restitution. This increase with application of a liquid layer was already mentioned before and was said to be a result of lubrication effect of the water. In the system with rough target the tangential coefficient of restitution is the same for dry and wet collisions. Therefore, it can be assumed that these lubrication effects are less active for the collision on a rough target.

In the middle diagram (b) the smooth system is compared to the system with rough particles. A similar effect as for the rough target is found: For the rough particles the tangential coefficient of restitution is the same for dry and wet collisions and equal to the tangential coefficient of restitution for dry collisions in the smooth system. Therefore, also for this system lubrication shows no effect.

The lower diagram (c) of Fig. 14 shows the tangential coefficient of restitution for the smooth and the completely rough systems for dry and wet collisions. For the rough system the application of a liquid layer also features no clear effect, as was already found in Fig. 14(a) and (b). Thus, it can be concluded, that lubrication effects in the tangential direction only act during collisions of smooth materials and can be neglected for rough systems. Furthermore, the tangential coefficient of restitution for the rough system is slightly lower than for the smooth system at collision angles higher than $40^{\circ}$, and thus the minimum seems to shift to higher collision angles. Both of these findings arise from higher friction resulting in more energy dissipation in the tangential direction and enhancement of rolling of the particles on the plate. This in turn leads to a shift of the transition of rolling to sliding and therefore to the shift of the minimum to higher collision angles.

An additional look at the standard deviations shows, that for the collisions of rough particles or target plates the standard deviations are mostly greater than for the smooth system. Some scatter always happens due to deviations from spherical shape and deformation or fracture of roughness peaks. However with increasing surface roughness the latter cause gets more dominant leading to increasing overall scatter as was found in this work. Montaine et al. (2011) investigated the influence of surface roughness on scatter during particle-wall collisions and reported similar results of increasing scatter due to surface roughness.

Although the surface roughness investigated in this work, which is below $1.5 \mu \mathrm{m}$, is quite small compared to surface roughness in real particulate systems, it still shows distinct influence on rebound behaviour. For higher surface roughness the influence on the coefficients of restitution might further increase, leading to even more energy dissipation and decreasing sliding due to higher friction.

\section{Conclusion}

The dependence of the normal and tangential coefficient of restitution on different parameters was experimentally studied for oblique collisions of dry particles on wet surfaces. Glass particles were used to impact on a glass target with collision angles of $0^{\circ}$ to $60^{\circ}$, a liquid layer thickness between 200 and $600 \mu \mathrm{m}$, surface tensions of 72.8 and $37.3 \mathrm{mN} \mathrm{m}^{-1}$ and liquid viscosities between 1 and $35.5 \mathrm{mPa}$ s. The influence of surface roughness was discussed as well. The main results can be summarized as follows.

1. The normal coefficient of restitution in the dry contact is constant in the investigated range of collision angles, while the tangential coefficient shows a minimum, which results from the transition from rolling to sliding of the particle on the target. For low collision angles the tangential coefficient of restitution features a strong scatter with a coefficient of variation of up to $50 \%$. At collision angles above $30^{\circ}$ the tangential coefficient of restitution increases with increasing collision angle.

2. The application of a liquid layer on the target decreases the normal coefficient of restitution approximately linear with increasing layer thickness. If a liquid layer is applied the tangential coefficient of restitution increases due to less friction. An increasing layer thickness has no further effect on the tangential coefficient of restitution.

3. An increasing liquid viscosity also decreases the normal coefficient of restitution resulting from a higher viscous force. In the range of collision angles higher than the before mentioned minimum an increasing viscosity leads to a slight increase of the tangential coefficient of restitution.

4. A change of surface tension shows no considerable influence on the normal or tangential coefficients of restitution 
in the investigated range. However, some influence on the formation and rupture of the liquid bridge as well as the wetting behaviour of the particles could be found. For decreasing surface tension the liquid bridge gets thinner and seems to rupture earlier. Rotation of the particle after collision seems to be enhanced for higher surface tensions.

5. For dry collisions surface roughness leads to a decrease of the normal coefficient of restitution. This decrease shows considerable effect only if both collision partners are rough, which leads to the assumption of the existence of a critical minimum surface roughness. In the wet case a rough target plate has no considerable influence on the normal coefficient of restitution, while a rough particle leads to an additional decrease. Regarding the tangential coefficient of restitution an increasing surface roughness seems to cancel the friction reducing effect of the liquid leading to the same tangential coefficient of restitution for wet and dry collisions for all collision angles.

The investigated system is strongly simplified in comparison to particle collisions in real systems. In an actual apparatus collisions mostly happen between two particles, which are often non-spherical. Therefore, the general trend found in this work will be superimposed with effects of shape, surface features and dynamics of the apparatus. However, the findings in a simplified system such as investigated in this work will still have validity in real particulate systems and help understanding particle behaviour.

\section{List of symbols}

$\delta_{l}$

$\varepsilon$

$\eta$

$E_{\text {kin }}$

$E_{k i n, R}$

$E_{\text {diss }}$

e

$e_{n}$

$e_{t}$

$m$

$R$

$S t^{*}$

v

$u_{n}$

$v_{R}$

$v_{t}$

$v_{\text {tot }}$

\section{layer thickness}

surface roughness

viscosity

kinetic impact energy

kinetic rebound energy

dissipative energy

coefficient of restitution

normal coefficient of restitution

tangential coefficient of restitution

mass

particle radius

critical Stokes number

velocity

normal velocity

rebound velocity

tangential velocity

total velocity $\mathrm{m}$

$\mathrm{m}$

Pa s

J

J

J

$-$

$-$

$\mathrm{kg}$

$\mathrm{m}$ $\mathrm{ms}^{-1}$

$\mathrm{ms}^{-1}$

$\mathrm{ms}^{-1}$

$\mathrm{ms}^{-1}$

$\mathrm{ms}^{-1}$

\section{Acknowledgements}

We gratefully acknowledge for the financial support: German Research Foundation (DFG), Germany, and Technology Foundation STW, The Netherlands. Project number HE 4526/9-1.

\section{References}

Antonyuk, S., Heinrich, S., Deen, N., Kuipers, H., 2009. Influence of liquid layers on energy absorption during particle impact.

Particuology 7 (4), 245-259, http://dx.doi.org/10.1016/ j.partic.2009.04.006.

Antonyuk, S., Heinrich, S., Tomas, J., Deen, N., van Buijtenen, M., Kuipers, J., 2010. Energy absorption during compression and impact of dry elastic-plastic spherical granules. Granular Matter 12 (1), 15-47, http://dx.doi.org/10.1007/ s10035-009-0161-3.

Barnocky, G., Davis, R.H., 1988. Elastohydrodynamic collision and rebound of spheres: experimental verification. Phys. Fluids 31 (6), 1324-1329, http://dx.doi.org/10.1063/1.866725.

Crüger, B., Salikov, V., Heinrich, S., Antonyuk, S., Sutkar, V., Deen, N., Kuipers, J., 2015. Coefficient of restitution for particles impacting on wet surfaces: an improved experimental approach. Particuology, http://dx.doi.org/10.1016/ j.partic.2015.04.002 (in Press).

Dong, H., Moys, M., 2006. Experimental study of oblique impacts with initial spin. Powder Technol. 161 (1), 22-31, http://dx.doi.org/10.1016/j.powtec.2005.05.046.

Dopfer, D., Palzer, S., Heinrich, S., Fries, L., Antonyuk, S., Haider, C., Salman, A.D., 2013. Adhesion mechanisms between water soluble particles. Powder Technol. 238, 35-49, http://dx.doi.org/10.1016/j.powtec.2012.06.029.

Ennis, B.J., Tardos, G., Pfeffer, R., 1991. A special volume devoted to the second symposium on advances in particulate technology a microlevel-based characterization of granulation phenomena. Powder Technol. 65 (1), 257-272, http://dx.doi.org/10.1016/0032-5910(91)80189-P.

Fu, J., Adams, M., Reynolds, G., Salman, A., Hounslow, M., 2004. Impact deformation and rebound of wet granules. Powder Technol. 140 (3), 248-257, http://dx.doi.org/10.1016/ j.powtec.2004.01.012.

Gollwitzer, F., Rehberg, I., Kruelle, C.A., Huang, K., 2012. Coefficient of restitution for wet particles. Phys. Rev. E 86, 011303, http://dx.doi.org/10.1103/PhysRevE.86.011303.

Glycerine Producers' Association, 1963. Physical Properties of Glycerine and its Solutions. Glycerine Producers' Association. Hastie, D., 2013. Experimental measurement of the coefficient of restitution of irregular shaped particles impacting on horizontal surfaces. Chem. Eng. Sci. 101, 828-836, http://dx.doi.org/10.1016/j.ces.2013.07.010.

Helenius, A., McCaslin, D.R., Fries, E., Tanford, C., 1979. Properties of detergents. In: Biomembranes Part G: Bioenergetics: Biogenesis of Mitochondria, Organization, and Transport, Vol. 56 of Methods in Enzymology. Academic Press, pp. 734-749, http://dx.doi.org/10.1016/0076-6879(79)56066-2.

Jain, D., Deen, N.G., Kuipers, J., Antonyuk, S., Heinrich, S., 2012. Direct numerical simulation of particle impact on thin liquid films using a combined volume of fluid and immersed boundary method. Chem. Eng. Sci. 69 (1), 530-540, http://dx.doi.org/10.1016/j.ces.2011.11.018.

Joseph, G.G., Zenit, R., Hunt, M.L., Rosenwinkel, A.M., 2001. Particle-wall collisions in a viscous fluid. J. Fluid Mech., 329-346, http://dx.doi.org/10.1017/S0022112001003470.

Kantak, A.A., Galvin, J.E., Wildemuth, D.J., Davis, R.H., 2005. Low-velocity collisions of particles with a dry or wet wall. Microgravity - Sci. Technol. 17 (1), 18-25, doi:10.1007/BF02870971.

Kharaz, A., Gorham, D., Salman, A., 2001. An experimental study of the elastic rebound of spheres. Powder Technol. 120 (3), 281-291, http://dx.doi.org/10.1016/S0032-5910(01)00283-2.

Liu, L.X., Litster, J.D., Iveson, S.M., Ennis, B.J., 2000. Coalescence of deformable granules in wet granulation processes. AIChE J. 46 (3), 529-539, http://dx.doi.org/10.1002/aic.690460312.

Ma, J., Liu, D., Chen, X., 2015. Rotational behavior of dry spheres obliquely impacting on liquid layers. Powder Technol. 270 (Part B), 418-423, http://dx.doi.org/10.1016/j.powtec.2014.08.042.

Ma, J., Liu, D., Chen, X., 2013. Experimental study of oblique impact between dry spheres and liquid layers. Phys. Rev. E 88, 033018, http://dx.doi.org/10.1103/PhysRevE.88.033018.

Montaine, M., Heckel, M., Kruelle, C., Schwager, T., Pöschel, T., 2011. Coefficient of restitution as a fluctuating quantity. Phys. Rev. E 84, 041306, http://dx.doi.org/10.1103/ PhysRevE.84.041306. 
Neuwirth, J., Antonyuk, S., Heinrich, S., Jacob, M., 2013. Cfd-dem study and direct measurement of the granular flow in a rotor granulator. Chem. Eng. Sci. 86, 151-163, doi:10.1016/j.ces.2012.07.005.

Salikov, V., Antonyuk, S., Heinrich, S., Sutkar, V.S., Deen, N.G., Kuipers, J., 2015. Characterization and cfd-dem modelling of a prismatic spouted bed. Powder Technol. 270 (Part B), 622-636, http://dx.doi.org/10.1016/j.powtec.2014.05.026, 6th International Workshop on Granulation: Granulation across the length scales.

Sutkar, V.S., Deen, N.G., Salikov, V., Antonyuk, S., Heinrich, S., Kuipers, J., 2015. Experimental and numerical investigations of a pseudo-2d spout fluidized bed with draft plates. Powder Technol. 270 (Part B), 537-547, http://dx.doi.org/10.1016/ j.powtec.2013.11.030, 6th International Workshop on Granulation: Granulation across the length scales.

Wu, C.-Y., yuan Li, L., Thornton, C., 2003a. Rebound behaviour of spheres for plastic impacts. Int. J. Impact Eng. 28 (9), 929-946, http://dx.doi.org/10.1016/S0734-743X(03)00014-9.
Wu, C.-Y., Thornton, C., Li, L.-Y., 2003b. Coefficients of restitution for elastoplastic oblique impacts. Adv. Powder Technol. 14 (4), 435-448, http://dx.doi.org/10.1163/156855203769710663.

Wu, C.-Y., Thornton, C., Li, L.-Y., 2009. A semi-analytical model for oblique impacts of elastoplastic spheres. Proc. R. Soc. Lond. A: Math. Phys. Eng. Sci. 465 (2103), 937-960, http://dx.doi.org/10.1098/rspa.2008.0221.

Thornton, C., 2009. A note on the effect of initial particle spin on the rebound behaviour of oblique particle impacts. Powder Technol. 192 (2), 152-156, http://dx.doi.org/10.1016/j.powtec.2008.12.015.

Thornton, C., Cummins, S.J., Cleary, P.W., 2011. An investigation of the comparative behaviour of alternative contact force models during elastic collisions. Powder Technol. 210 (3), 189-197, http://dx.doi.org/10.1016/j.powtec.2011.01.013.

Thornton, C., Cummins, S.J., Cleary, P.W., 2013. An investigation of the comparative behaviour of alternative contact force models during inelastic collisions. Powder Technol. 233, 30-46, http://dx.doi.org/10.1016/j.powtec.2012.08.012. 